\title{
Racial and Ethnic Analysis of Birth Weight Trends among Full-Term Singleton Newborns Delivered in a Prosperous Multicultural Society
}

\author{
Husam Salama*, Hilal Al Rifai, Sawsan Al-Obaidly, Mai Al Qubasi, Nawal El Saeed, \\ Ashraf Mansour, Amani Saeed
}

Women's Wellness and Research Center, Hamad Medical Corporation, Doha, State of Qatar

Email: ^Hsalama1@hamad.qa, Halrifai@hamad.qa, Salobaidly@hamad.qa, Maiqubaisi@hamad.qa,

NSAEED@hamad.qa, amansour2@hmc.org.qa, Aibrahim10@hmc.org.qa

How to cite this paper: Salama, H., Al Rifai, H., Al-Obaidly, S., Al Qubasi, M., El Saeed, N., Mansour, A. and Saeed, A. (2021) Racial and Ethnic Analysis of Birth Weight Trends among Full-Term Singleton Newborns Delivered in a Prosperous Multicultural Society. Open Journal of Obstetrics and Gynecology, 11, 1791-1802.

https://doi.org/10.4236/ojog.2021.1112167

Received: October 20, 2021

Accepted: December 25, 2021

Published: December 28, 2021

Copyright $\odot 2021$ by author(s) and Scientific Research Publishing Inc. This work is licensed under the Creative Commons Attribution International License (CC BY 4.0).

http://creativecommons.org/licenses/by/4.0/ (c) (i) Open Access

\begin{abstract}
Objectives: This study aims to describe birth weight and its variations concerning maternal characteristics as well as to standardize birth weight curves for Qatari and expatriate's newborn population born in the state of Qatar. Methods: PEARL-Peristat registry is a National maternal-neonatal observation epidemiologic database project where both maternal and neonatal cohort data are collected to evaluate specified outcomes for a population defined by a disease, conditions, or exposures. Results: Out of 50,535 singleton deliveries, only 44,178 live-born infants were included in this study. The LBW rate has remained constant since 2011 and was reported as $2.4 \%$ in males and $3.5 \%$ in females. The average total LBW was 3\%. The lowest incidence of LBW was seen in maternal age between 30 - 45 years. There was a marginal increase in the incidence of LBW among mothers less than 20 years of age. The incidence of LBW among Qatari mothers was reported as $2.6 \%, 2.2 \%$, and $2.4 \%$ in years 2011, 2012, 2017 respectively with a significant difference when compared to expatriates' newborns particularly in the year 2017 (p-value $<0.001$ ). Moreover, among Qatari newborns, there is a significant rise in the rate of LBW from 2011 to $2017,2.9 \%$ to $4.1 \%$ (p-value $\geq 0.007$ ). The expatriate's population received $69 \%$ of all maternal hospital services offered in government hospitals. Conclusion: The birth weight of newborns delivered in the state of Qatar is to a large extent consistent with the international birth weight figures for both Qatari and expatriate newborns delivered in Qatar. Low birth weight is increasing particularly among young mothers. The lowest rate of LBW was reported among mothers aged above 29 years old. Large for the date was observed among mothers older than 29 years of age.
\end{abstract}




\section{Keywords}

Birth Weight, Newborn, Qatar, Low Birth Weight, Large Birth Weight

\section{Introduction}

The state of Qatar is one of the wealthiest countries in the world with the fast development of health care systems. The growing level of prosperity and affluence observed in the state of Qatar has resulted in a steady influx of expatriates who seek a better lifestyle with improved opportunities. Peristat registry is a national perinatal epidemiological observational database where extensive medical and social cohort data are being collected to evaluate specified outcomes for a population defined by a disease, condition, or exposure, and that serves one or more predetermined scientific, clinical, or policy purposes. This database is collected over a long period prospectively which enables investigators to run several epidemiological analyses related to maternal and neonatal health care outcomes. Secular trends in birth weight can indicate changes in maternal health and nutrition. Newborns with birth weights outside the normal range are at higher risks of mortality and morbidity in the perinatal period and later in life [1] [2] [3] [4]. Small or large for gestational age is common indicator of restricted or excessive fetal growth. Previous studies have shown that SGA newborns had an increased risk of respiratory complications, hypoglycemia, and necrotizing enterocolitis during the immediate postnatal period, neurological impairment in childhood, cardiovascular disease, and type 2 diabetes mellitus in adulthood [5], while LGA is associated with increased risk of birth trauma, cesarean section, and postpartum hemorrhage as well as obesity, metabolic syndrome and type 2 diabetes mellitus in adulthood [3] [6]. Therefore, examining trends in the incidence of SGA and LGA may be useful in evaluating the health of the population. Recently, a multi-native standard for newborn weight is published by the Inter-native Fetal and Newborn Growth Consortium for the 21st Century (INTERGROWTH21st) [7] [8] [9] [10] [11]. This study demonstrated that in mothers free from social, nutritional, medical, and other constraints on fetal growth, the growth of newborns around the world is remarkably similar. The goal of this study is to compare the birth weight of newborns born in Qatar over 7 years and investigate whether economic development is associated with any changes in newborn birth weight.

\section{Methods}

This is a longitudinal retrospective study in state-run hospital-based facilities in Qatar, targeting maternal and newborn registries with data bridging the perinatal to postpartum periods. Data for this study is derived from Qatar's perinatal registry developed in 2011 and reactivated in 2016 as the Qatar Pearl-Peristat registry. The study is funded by the Qatar Native Research fund [QNRF] and 
sponsored by the medical research center of Hamad Medical Corporation. The registry contains data collected from all government hospitals with delivery facilities in Qatar spanning the perinatal to postpartum periods. By utilizing patient care records, the registry aims to examine the short and long-term maternal and newborn health outcomes. Besides, the study seeks to explore the development of specified sub-cohorts with the intent of improving reproductive health outcomes of the Qatar population. The registry houses delivery cohorts from 2011 to 2012 (35,000 deliveries) as the first phase and from 2019 to 2019 as a second phase, which is targeting around 35,000 deliveries within the whole country. The registry has excluded cases from the private sector as it represents only less than $10 \%$ of the total deliveries in Qatar and does not apply the same electronic health record system. The primary registry data is collected from the universal electronic medical records (EMR Cerner ${ }^{\circledR}$ ) that link all the government hospitals. Additionally, a social data questionnaire administered after delivery is used to collect socio-economic and demographic health information to address the social status of pregnant women. The research team of the registry includes trained 12 research assistants dedicated to collecting patient data either directly from the family [social data] or the EMR [electronic clinical data-Cerner ${ }^{\circledR}$ ] guided by a full-time qualified research associate. The collected data is analyzed and stored in a specially designed program created by the Dendrite ${ }^{\varpi}$ database solution while analyzed using both Dendrite ${ }^{\oplus}$ and SPSS ${ }^{\oplus}$ version 22.

Population: Only singleton viable newborn deliveries are included in this study. Multiple pregnancies, preterm newborns less than 37 weeks, and severe congenital and/or chromosomal abnormalities are excluded from this current report study.

STATISTICAL ANALYSIS Records for singleton pregnancies born at 37 weeks gestation and above are retrieved from the PEARL-Peristat Registry in Excel format. Data for a total of 50,535 singleton births are retrieved following which extreme or aberrant maternal age, birth weight, or gestational ages are removed from dataset (Figure 1). Test cases from some years and additional records are also removed for various reasons (Figure 1). There are a total of 44,178 births used finally; (2616 preterm and 41,562 term newborns). Birth weight is examined within the following cohorts: year of delivery, nativity (Native vs. Expatriates), maternal age at delivery, newborn gender, and the duration of pregnancy. For each group examined, frequencies and percentages or percentiles are calculated. Differences in proportion are tested using Pearson's Chi-square test with statistical significance set at $\mathrm{P}$ value $<0.05$. Results are presented as histograms, bar charts, and percentile graphs.

\section{Results}

Out of 50,535 singleton deliveries, only 44,178 live-born infants are included in this study (Figure 2). The LBW rate continued to be the same since 2011 and is reported as a total of $2.4 \%$ in the male gender and $3.5 \%$ in the female gender. 


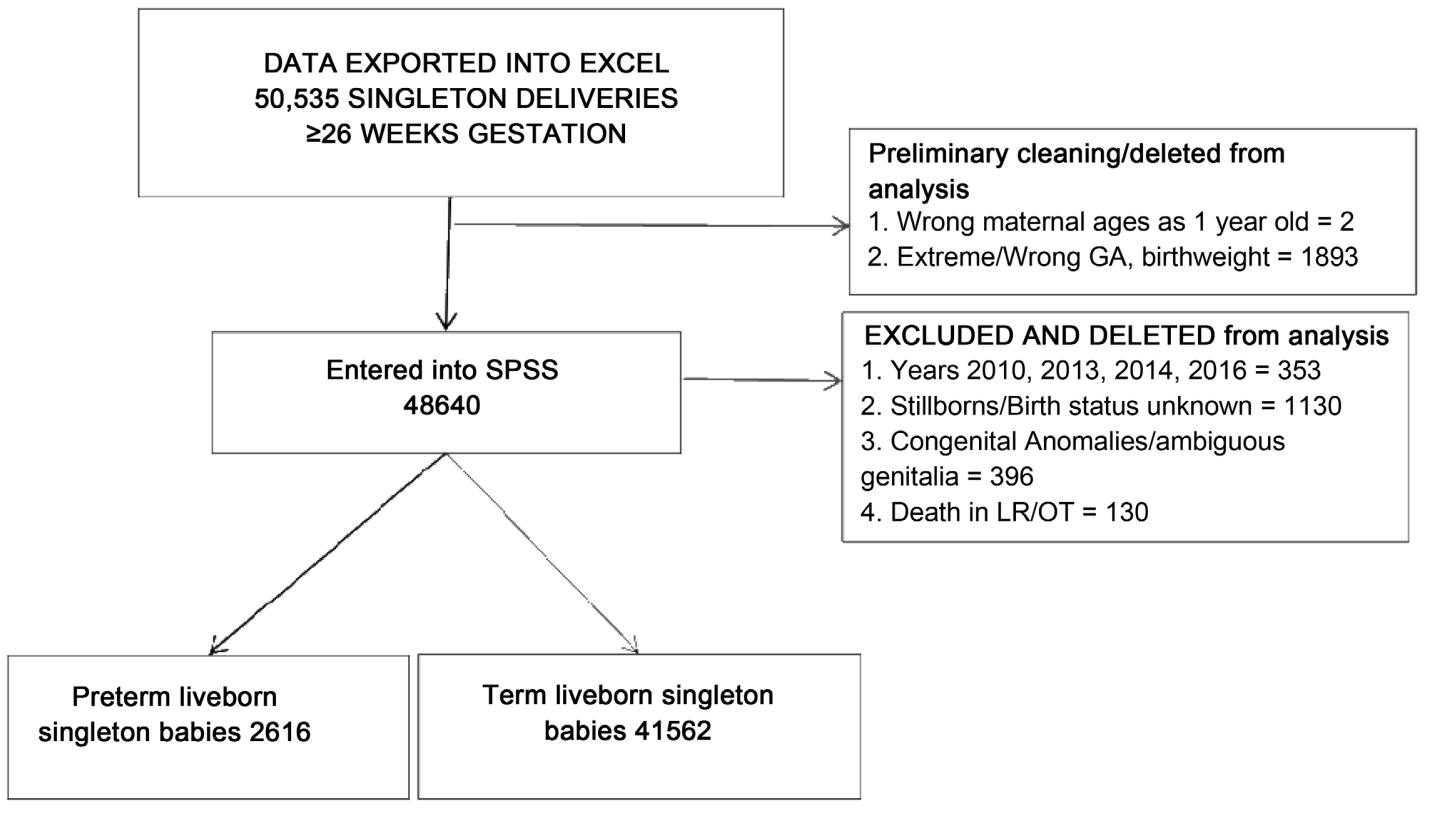

Figure 1. Summary of singleton deliveries included in the analysis between 2011 and 2019.

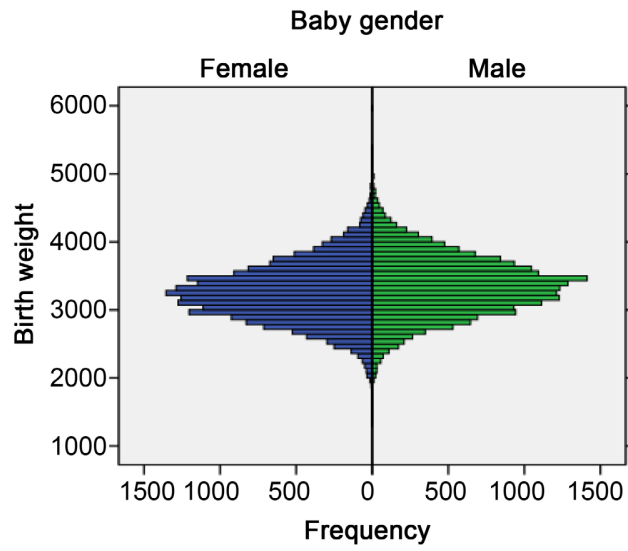

(a)

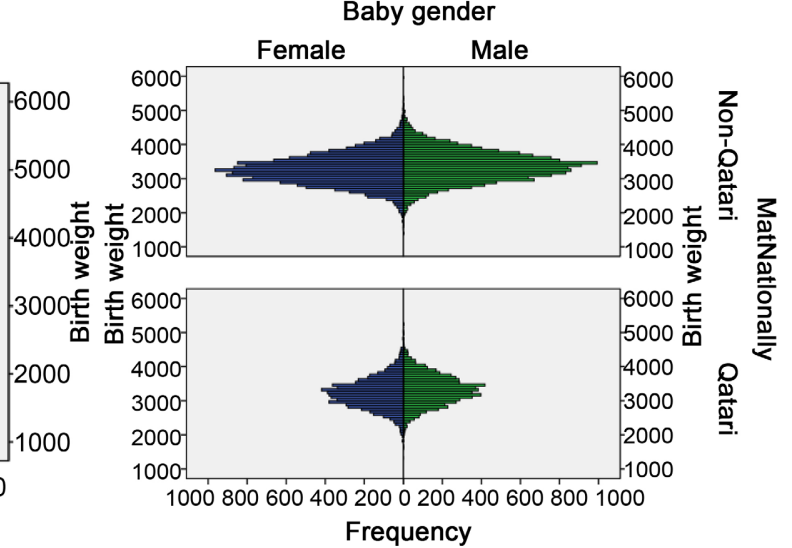

(b)

Nationality distribution

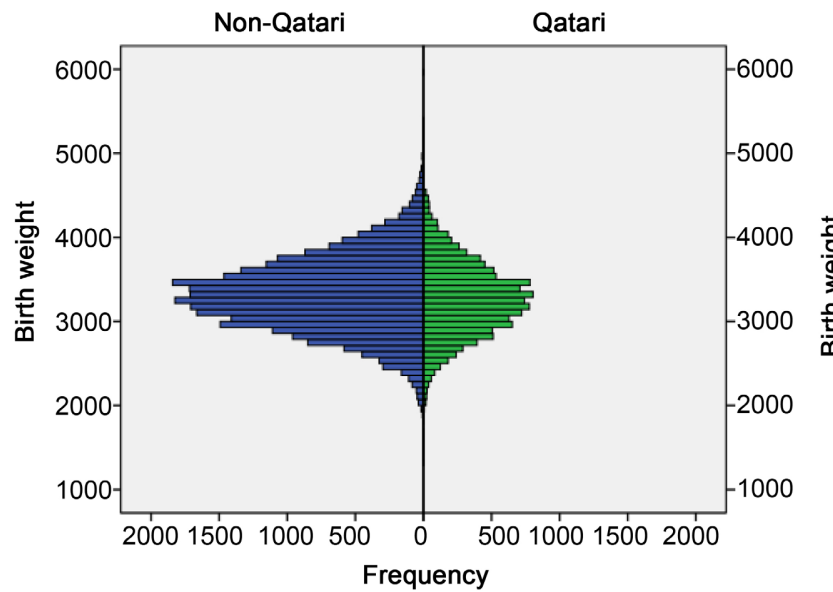

(c)

Figure 2. Birth weight distribution by newborn gender (a), nativity (b), gender and nativity (c). 
The expatriate population received $69 \%$ of all government maternal hospital services (Figure 3). Moreover, among Native newborns, there is a significant rise in the rate of LBW from 2011 to 2019, 2.9\% to 4.1\% (P-value 0.007). (Figure 4) The average total LBW is $3 \%$. However, it is noted to be the lowest among maternal age between 30 - 45 years (Figure 5). LBW analysis per maternal age showed a

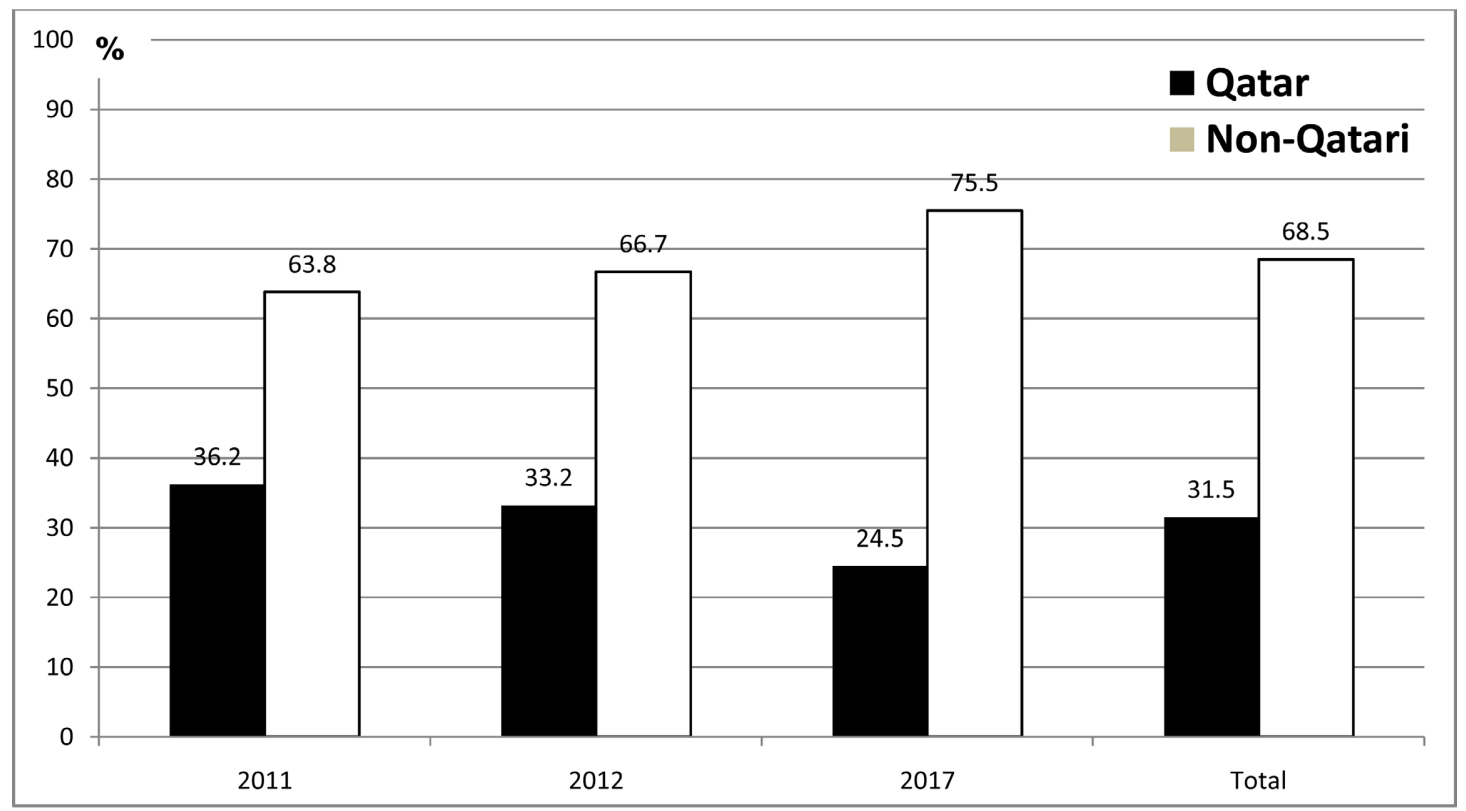

Figure 3. Maternal nativity distribution in 41,000 term singleton deliveries \%.

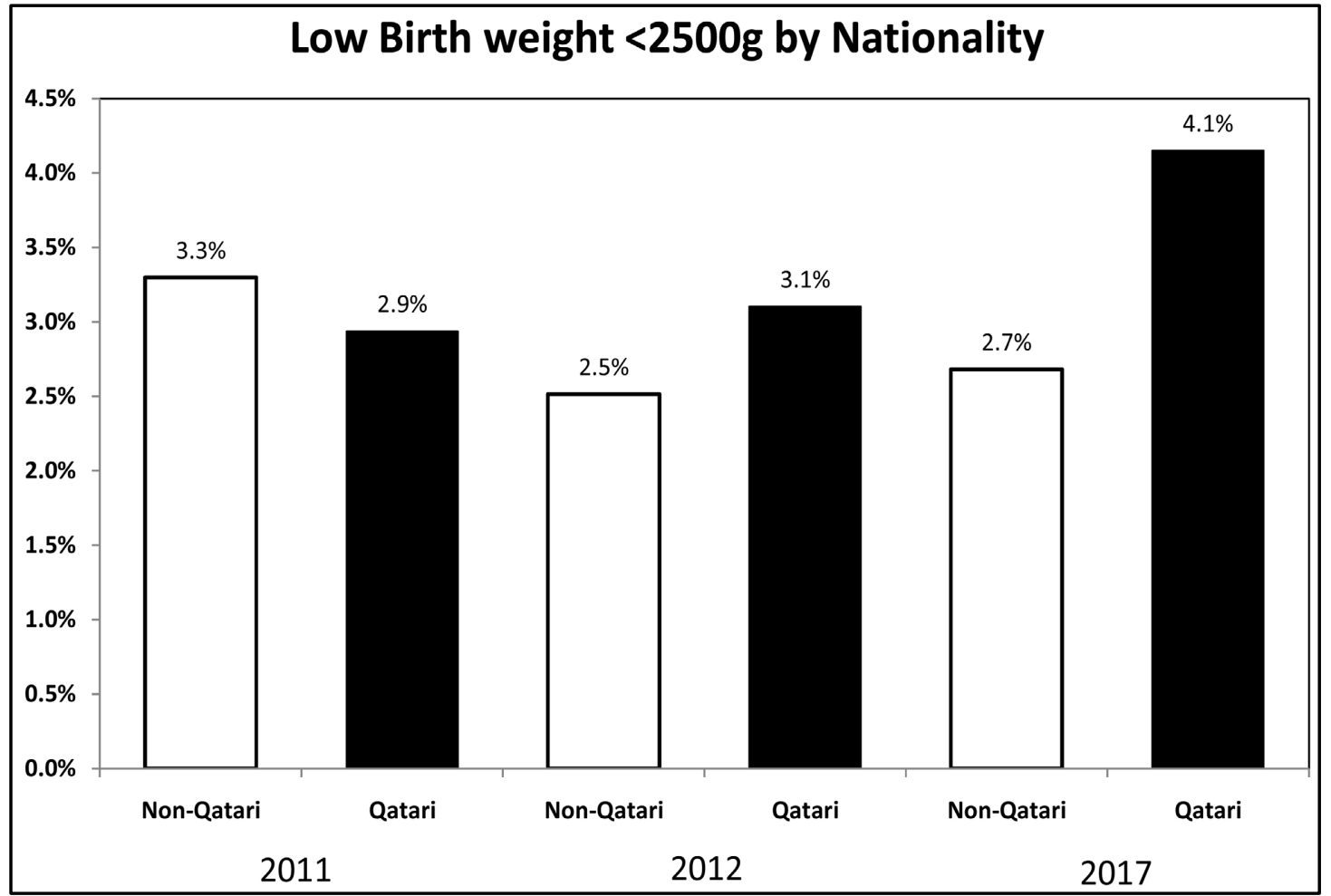

Figure 4. Low birth weight according to nativity (\%) in 41,000 term singleton deliveries. 


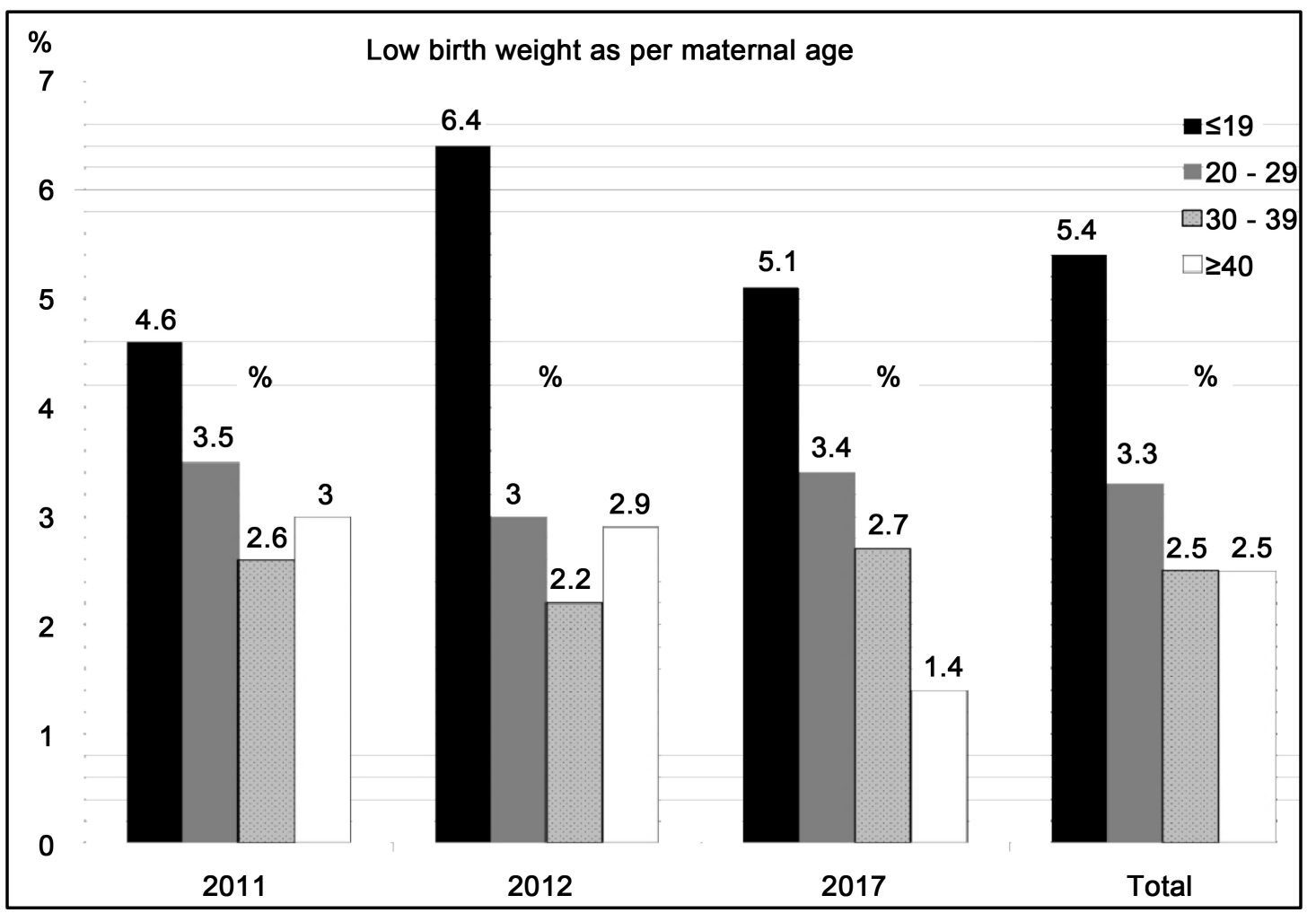

Figure 5. Low birth weight as per maternal age in 41,000 term singleton deliveries (\%).

marginal increase among mothers less than 20 years of age. The rate of LBW among Native mothers is reported as $2.6 \%, 2.2 \%$, and $2.4 \%$ in years 2011, 2012, 2019 , respectively, with a significant difference when compared to expatriate newborns, particularly in the year 2019 (P-value < 0.001). As well, LBW among female births more than male birth $2.4 \%$ vs $3.4 \%$ (Figure 6). Large for the date is reported as 6.3 overall, noted to be more prevalent among older mothers with the highest recorded among mothers aged 35 years and above. (Figure 7)

\section{Discussion}

Although growth patterns among children are similar, growth variations exist due to demographic, cultural, nutritional, and geographical factors making it vital to standardize growth charts based on the country where the study is conducted. Keeping this rationale in mind, we computed the birth weight variations concerning certain maternal characteristics in the state of Qatar. Considering the sample size and time frame, this study is one of the largest available in literature aimed at synthesizing native growth curves covering its diverse population. The sample size and newborn population distribution were homogeneously spread among both Native and expatriates. (Figure 2) Among the 41,000 singleton deliveries analyzed in this analysis, a staggering number of deliveries (68.5\%) are non-native residents, which highlights the magnitude of healthcare expenditure directed towards the expatriate population. (Figure 3) The rise in the rate of LBW from 2011 to 2017 can be explained by a rapid increase in the number of 


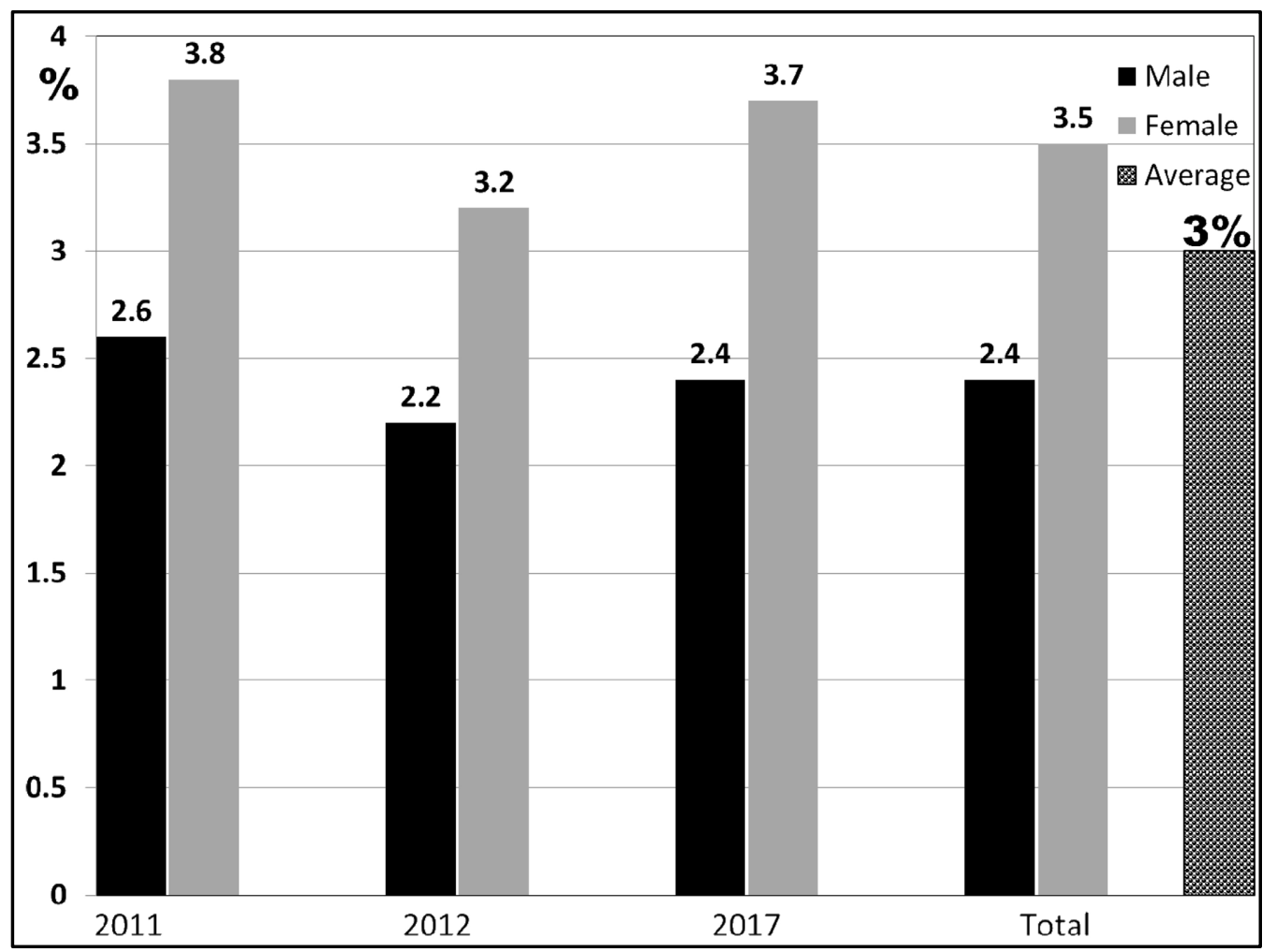

Figure 6. Low birthweight according to gender in 41,000 term singleton deliveries.

\begin{tabular}{|c|c|c|c|c|c|c|c|}
\hline$B W<2500$ & & & & $B W=2500-3999$ & & & $B W>3999$ \\
\hline Total $3.3 \%$ & & & & & & & $5.2 \%$ \\
\hline$\geq 40$ yrs $2.9 \%$ & & & & & & & $7.80 \%$ \\
\hline $30-39$ yrs $2.5 \%$ & & & & & & & $6.90 \%$ \\
\hline F $20-29$ yrs $3.8 \%$ & & & & & & & $3.8 \%$ \\
\hline$\leq 19$ yrs $5.10 \%$ & & & & & & & $2.6 \%$ \\
\hline Total $4.1 \%$ & & & & & & & $4.10 \%$ \\
\hline$\geq 40$ yrs $1.80 \%$ & & & & & & & $3.60 \%$ \\
\hline$\tilde{\delta}^{\circ} 30-39$ yrs $3.80 \%$ & & & & & & & $6.0 \%$ \\
\hline$N_{20-29 \text { yrs } 4.70 \%}$ & & & & & & & $2.6 \%$ \\
\hline$\leq 19 \mathrm{yrs} \overline{4.70 \%}$ & & & & & & & $0.00 \%$ \\
\hline Total $3.1 \%$ & & & & & & & $5.30 \%$ \\
\hline$\geq 40 \mathrm{yrs}$ & & & & & & & $10.5 \%$ \\
\hline$N^{2} 30-39 \mathrm{yrs} 2.30 \%$ & & & & & & & $6.50 \%$ \\
\hline $\mathrm{N}_{20}-29 \mathrm{yrs} .30 \%$ & & & & & & & $4.1 \%$ \\
\hline$\leq 19 \mathrm{yrs} \quad 6.80 \%$ & & & & & & & $8.13 \%$ \\
\hline Total $2.90 \%$ & & & & & & & $5.70 \%$ \\
\hline$=\quad \geq 40 \mathrm{yrs} 3.1 \%$ & & & & & & & $8.20 \%$ \\
\hline $\bar{\aleph}_{3} 30-39 \mathrm{yrs}$ & & & & & & & $7.90 \%$ \\
\hline $20-29$ yrs $3.70 \%$ & & & & & & & $4.10 \%$ \\
\hline$\leq 19$ yrs $4.00 \%$ & & & & & & & $3.4 \%$ \\
\hline $10 \%$ & $20 \%$ & $30 \%$ & $40 \%$ & $60 \%$ & $70 \%$ & $80 \%$ & $100 \%$ \\
\hline
\end{tabular}

Figure 7. Birth weight variations among 12,992 Native singleton term infants. 
expatriates living in the state of Qatar from 1.2 million to 2.1 million in 2017 majority are working class from the middle east, Indian subcontinent, and far east countries. [12] Low birth weights in full-term singleton newborns are noted to be consistently high among female newborns for all the years studied with an overall incidence of 3\%. Mothers aged less than 19 years are reported to have the highest incidence of low birth weight newborns reflecting the need for targeted care in the teenage group to prevent morbidity and mortality. However, mothers aged above 30 years had the lowest rate. This can be explained by a less responsible healthy lifestyle, worse socioeconomic and reproductive conditions, and less attention to antenatal care when compared to other age groups [13] [14].

Moreover, a rise in the rate of low birth weight newborns is noted from 2011 to 2019 , from $2.9 \%$ to $4.1 \%$ which could have a bearing on the existing native health care guidelines and policies. The highest incidence of large for gestational weight newborns is noted universally among mothers aged more than 40 years. (Figure 5 \& Figures 8-10) One of the limitations of the study that could

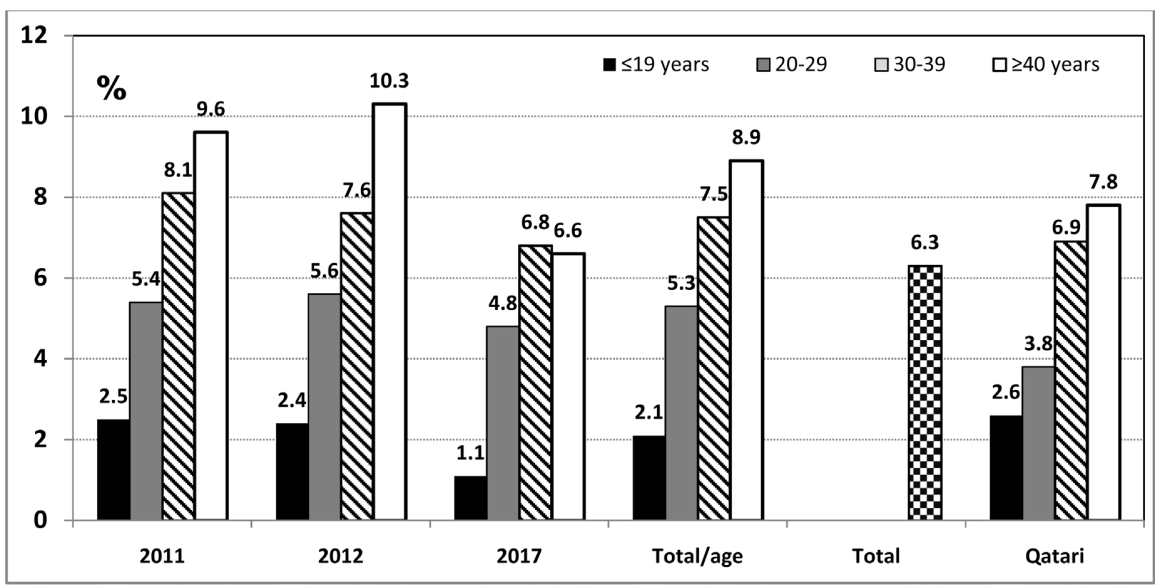

Figure 8. Large birth weight as per maternal age in 41,000 term singleton deliveries (\%).

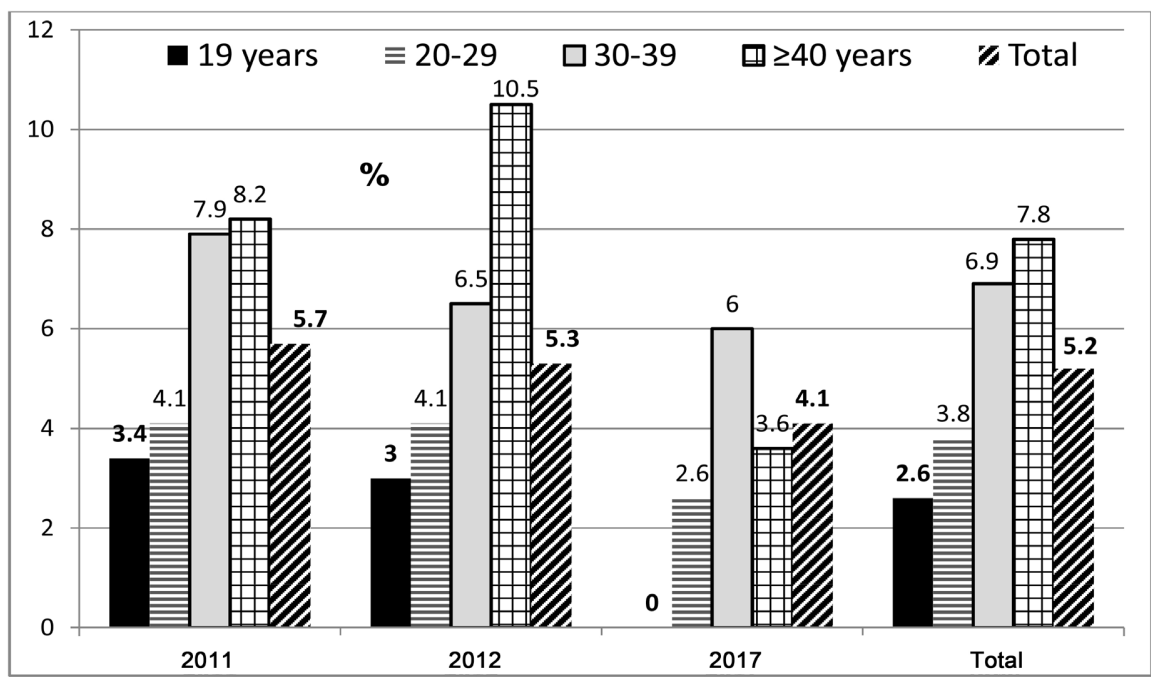

Figure 9. Large birth weights as per maternal age in 12,992 term singleton Native deliveries (\%). 

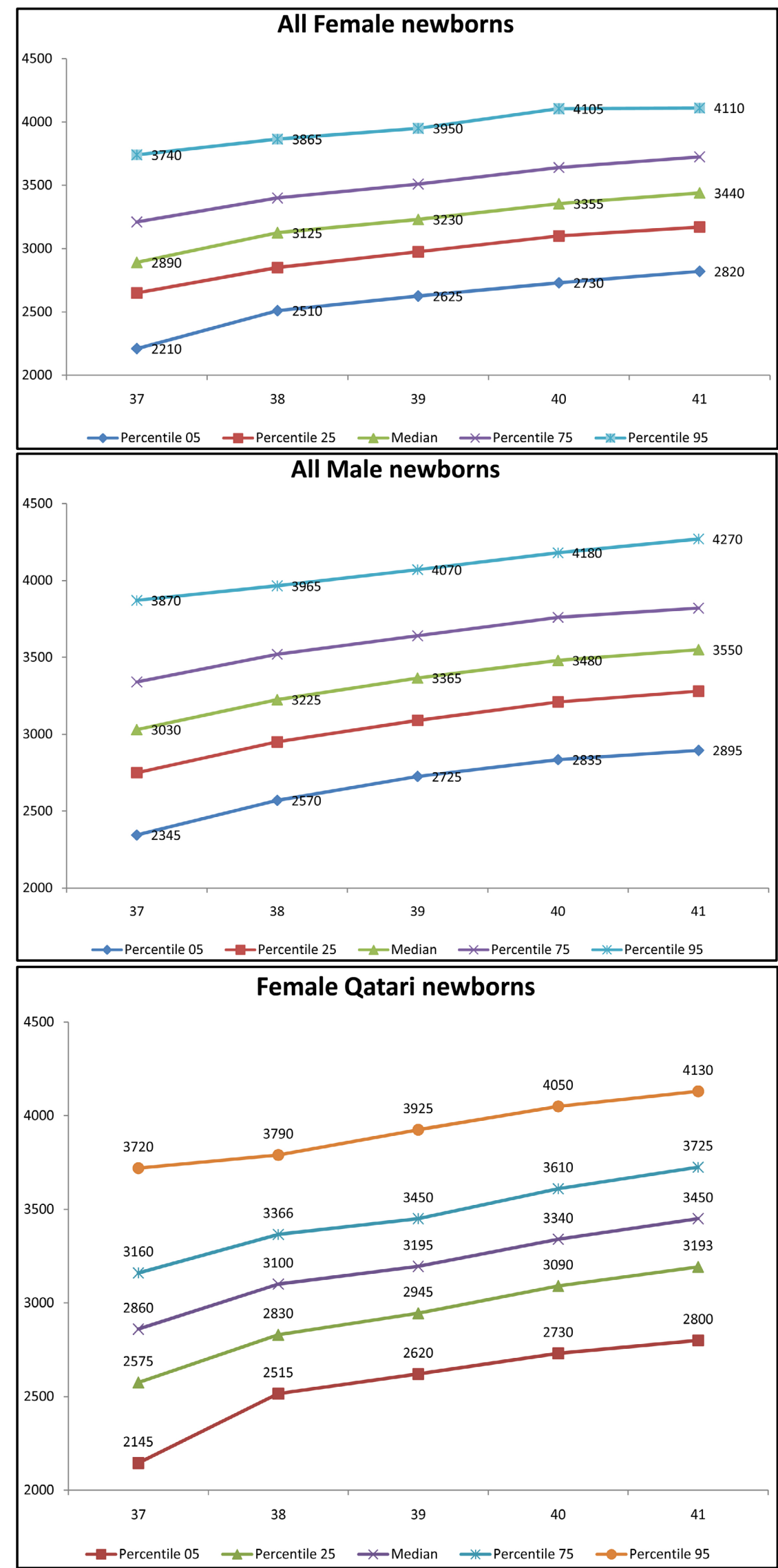

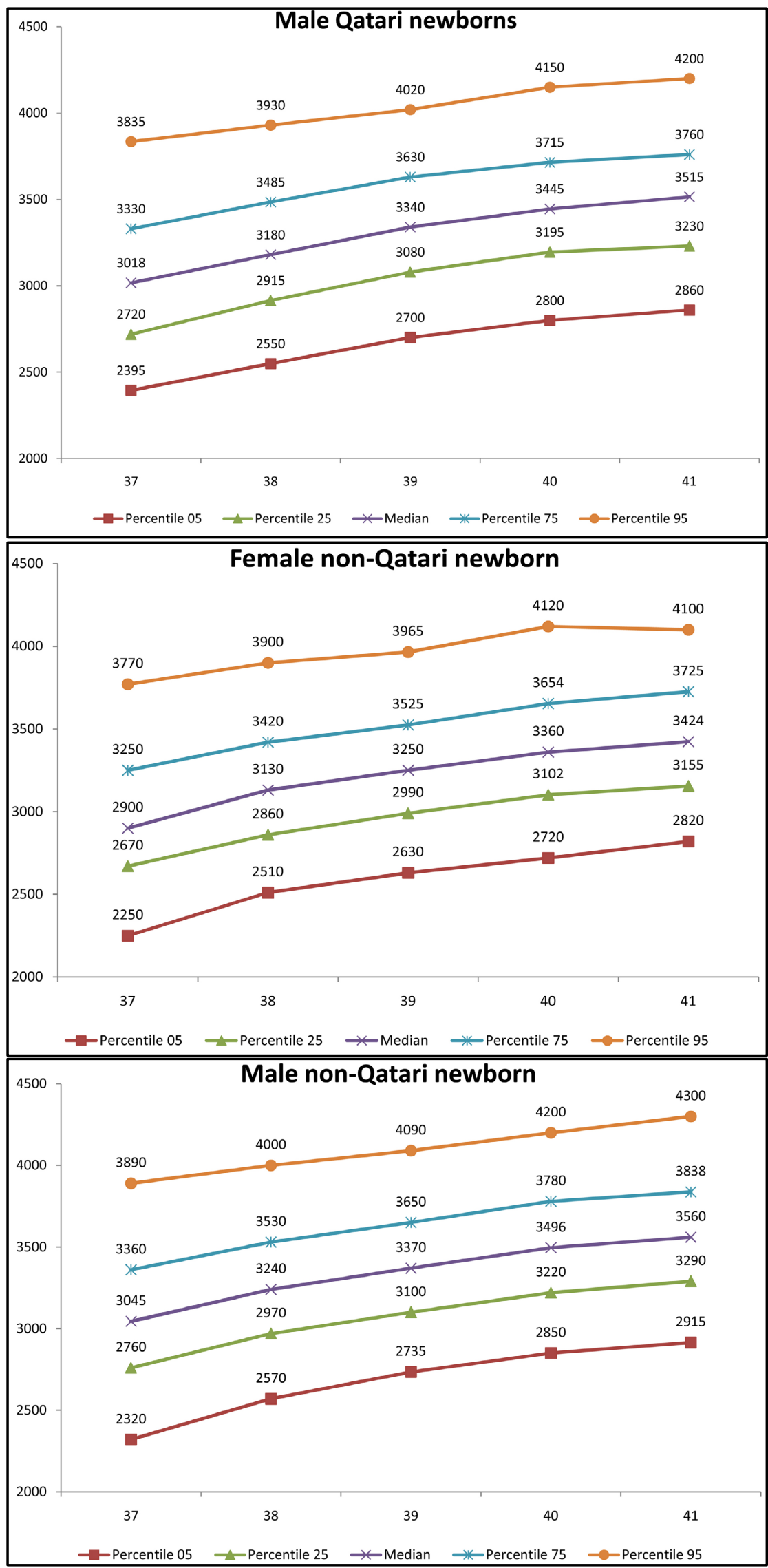


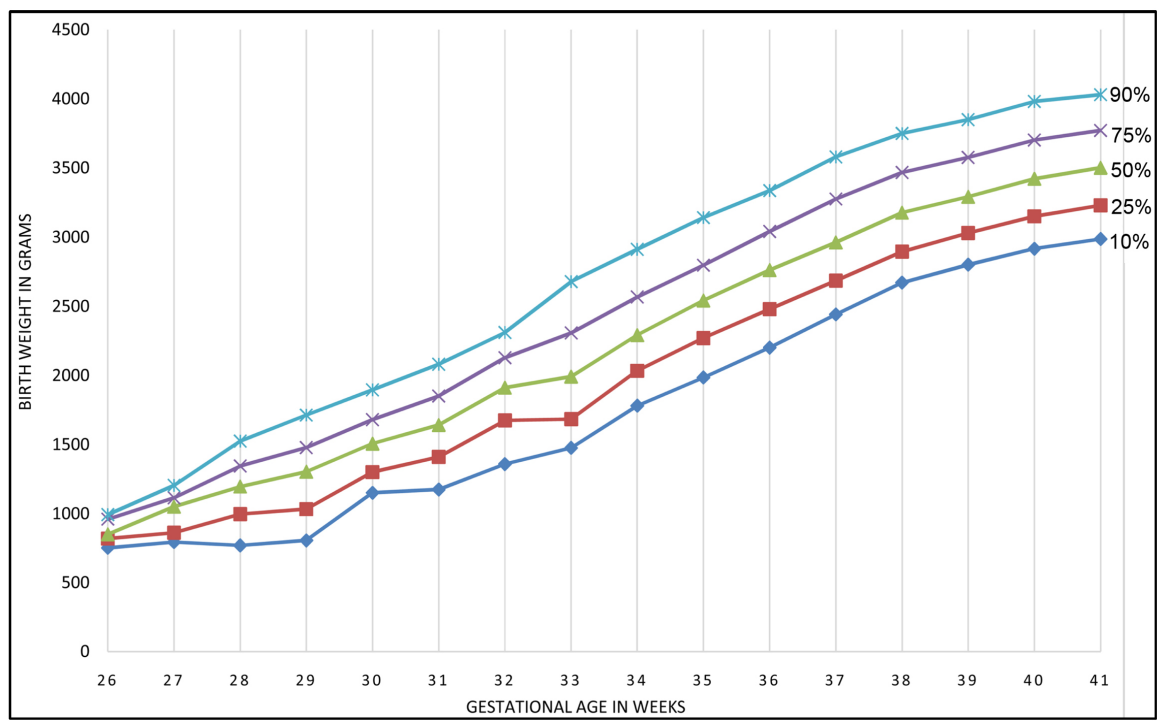

Figure 10. Birth weight curves of Native and expatriates full term newborns delivered in Qatar.

confound the interpretation of our results is the lack of data retrieval for successive years. However, the sample size distribution remained homogeneous regarding gender and nativity throughout the years of the study.

\section{Conclusion}

In this analysis, we attempted to paint a clear description of the birth weight of singleton newborn infants born in the state of Qatar and highlighted the main effects related to gender, maternal age, and geographical origin. The rapid influx of expatriates to the country during the study period was associated with an increased rate of LBW. The lowest rate of LBW was noted among mothers above 30 years of age which reflects the impact of a mature lifestyle of mature women. Understanding the statistical data derived from this study could lead to better implementation of national healthcare programs with a greater focus on mothers belonging to extreme ends of the age spectrum thereby improving neonatal outcomes.

\section{Conflicts of Interest}

The authors declare no conflicts of interest regarding the publication of this paper.

\section{References}

[1] Basso, O., Wilcox, A.J. and Weinberg, C.R. (2006) Birth Weight and Mortality: Causality or Confounding? American Journal of Epidemiology, 164, 303-311. https://doi.org/10.1093/aje/kwj237

[2] Wilcox, A.J. (2001) On the Importance and the Unimportance of Birthweight. International Journal of Epidemiology, 30, 1233-1241. https://doi.org/10.1093/ije/30.6.1233 
[3] Zimbeck, M., Mohangoo, A. and Zeitlin, J. (2009) The European Perinatal Health Report: Delivering Comparable Data for Examining Differences in Maternal and Infant Health. European Journal of Obstetrics \& Gynecology and Reproductive Biology, 146, 149-151. https://doi.org/10.1016/j.ejogrb.2009.07.017

[4] Kramer, M.S. (1987) Determinants of Low Birth Weight: Methodological Assessment and Meta-Analysis. Bull World Health Organ, 65, 663-737.

[5] Johnston, L.B., Clark, A.J. and Savage, M.O. (2002) Genetic Factors Contributing to Birth Weight. Archives of Disease in Childhood - Fetal and Neonatal Edition, 86, F2-F3. https://doi.org/10.1136/fn.86.1.F2-a

[6] Agency for Healthcare Research and Quality (2003) Native Healthcare Disparities Report. https://www.ahrq.gov/patient-safety/resources/index.html

[7] International Fetal and Newborn Growth Consortium (2009) The International Fetal and Newborn Growth Standards for the 21st Century (INTERGROWTH-21st) Study Protocol. https://www.intergrowth21.org.uk/

[8] Salameh, K., Rahman, S., Al-Rifai, H., Masoud, A., Lutfi, S., Abdouh, G., Omar, F., Khan, S.I. and Bener, A. (2009) An Analytic Study of Trends in Perinatal and Neonatal Mortality Rates in the State of Qatar over a 30 Years Period (1977-2007): A Comparative Study with Regional and Developed Countries. Journal of Perinatology, 29, 765-770. https://doi.org/10.1038/jp.2009.89

[9] Rahman, S., Salameh, K., Bener, A. and El Ansari, W. (2010) Socioeconomic Associations of Improved Maternal, Neonatal, and Perinatal Survival in Qatar. International Journal of Women's Health, 2, 311-318. https://doi.org/10.2147/IJWH.S12426

[10] Parappil, H., Rahman, S., Salama, H., Al Rifai, H., Parambil, N.K. and El Ansari, W. (2010) Outcomes of $28^{+1}$ to $32^{+0}$ Weeks Gestation Newborns in the State of Qatar: Finding Facility-Based Cost-Effective Options for Improving the Survival of Preterm Neonates in Low Income Countries. International Journal of Environmental Research and Public Health, 7, 2526-2542. https://doi.org/10.3390/ijerph7062526

[11] Rajaratnam, J.K., Marcus, J.R. and Flaxman, A.D. (2010) Neonatal, Postneonatal, Childhood, and under-5 Mortality for 187 Countries, 1970-2010: A Systematic Analysis of Progress towards Millennium Development Goal 4. Lancet, 375, 1988-2008. https://doi.org/10.1016/S0140-6736(10)60703-9

[12] De Bel-Air, F. and Gulf Labour Markets and Migration Programme (GLMM) (2018) Demography, Migration, and Labour Market in Qatar-UPDATED June 2017. https://www.researchgate.net/publication/323129801

[13] Ministério da Saúde (1990) Sistema de Informações Sobre Nascidos Vivos-SINASC. Brasília (DF).

[14] Slap, G.B. and Schwartz, J.S. (1989) Risk Factors for Low Birth Weight to Adolescent Mothers. Journal of Adolescent Health Care, 10, 267-274. https://doi.org/10.1016/0197-0070(89)90056-9

\section{Abbreviations}

GA: Gestation age; LGA: Large for gestational age; LBW: Low Birth weight; SGA: Small for gestation age. 